\title{
Mechanism of Action of Cholecystokinin on Colonic Motility in Isolated, Vascularly Perfused Rat Colon
}

\author{
Byeong-Seong Ko, ${ }^{1}$ Joung-Ho Han, ${ }^{1}$ Jee-In Jeong, ${ }^{2}$ Hee-Bok Chae, ${ }^{2}$ Seon-Mee Park, ${ }^{2}$ Sei-Jin Youn ${ }^{2 *}$ and Kae-Yol Lee ${ }^{3}$ \\ ${ }^{1}$ Department of Internal Medicine, Cheongju St. Mary's Hospital, Cheongju, Chungcheongbuk-do, Korea, ${ }^{2}$ Department of Internal Medicine, \\ Chungbuk National University College of Medicine, Cheongju, Chungcheongbuk-do, Korea, ${ }^{3}$ Department of Internal Medicine, School of \\ Medicine, University of Rochester, NY, USA
}

\section{Background/Aims}

It is generally believed that cholecystokinin (CCK) stimulates colonic motility, although there are controversial reports. It has also been suggested that postprandial peptide YY (PYY) release is CCK-dependent. Using a totally isolated, vascularly perfused rat colon, we investigated: (1) the roles of CCK and PYY on colonic motility, (2) to determine if CCK modulates PYY release from the colon to influence the motility and (3) to clarify whether the action of CCK and PYY on colonic motility is mediated via the influence of cholinergic input.

\section{Methods}

An isolated whole rat colon was used. Luminal pressure was monitored via microtip catheter pressure transducers from proximal and distal colon. After a control period, CCK-8 or PYY was administerd intraarterially with or without an anti-PYY serum, loxiglumide or atropine at 12,60 and 240 pM. Each dose was given for a period of 15-minute and the contractile response was expressed as \% changes over basal. PYY concentration in the portal effluent was determined by radioimmunoassay.

\section{Results}

Exogenous CCK-8 increased colonic motility which paralleled the increase in PYY release in the portal effluent. Exogenous PYY also significantly increased colonic motility although it was less potent than CCK. The stimulating effect of CCK-8 was significantly inhibited by an anti-PYY serum, and was completely abolished by loxiglumide, and almost completely abolished by atropine.

\section{Conclusions}

CCK increases colonic motility via CCK 1 receptor and it is mediated partly by PYY. Cholinergic input is required for the increased motility by either PYY or CCK.

(J Neurogastroenterol Motil 2011;17:73-81)

\section{Key Words}

Cholecystokinin; Colon; Peptide YY

Received: July 1, 2010 Revised: October 19, 2010 Accepted: October 28, 2010

(c) This is an Open Access article distributed under the terms of the Creative Commons Attribution Non-Commercial License (http://creativecommons. org/licenses/by-nc/3.0) which permits unrestricted non-commercial use, distribution, and reproduction in any medium, provided the original work is properly cited.

${ }^{*}$ Correspondence: Sei-Jin Youn, MD

Department of Internal Medicine, Chungbuk National University College of Medicine, 410 Seong bong-ro, Heungduk-gu, Cheongju, Chungcheongbuk-do 361-711, Korea

Tel: +82-43-269-6357, Fax: +82-43-273-3252, E-mail: sjyoun@chungbuk.ac.kr

Financial support: None.

Conflicts of interest: None. 


\section{Introduction}

Cholecystokinin (CCK) was indentified in 1966 as a 33 amino acid peptide, extracted from porcine intestine. ${ }^{1}$ There are 2 cell types producing CCK: (1) endocrine cells of the small intestine and (2) various neurons in the gastrointestinal tract and central nervous system. CCK is a peptide known to act both as a circulating hormone and as a neurotransmitter. ${ }^{2,3}$

CCK stimulates gallbladder contraction and pancreatic enzyme secretion, and inhibits gastric emptying which facilitates the nutrients digestion and absorption from gut. It was reported that CCK stimulates colonic motility in vitro ${ }^{4}$ as well as in vivo, ${ }^{5-7}$ although there have been controversial reports. ${ }^{8,9}$

$\mathrm{CCK}$ and gastrin comprise a family of gastrointestinal peptides that share an identical carboxyl-terminal pentapeptide sequence. Sulfation of the tyrosine ( $\mathrm{Tyr}$ ) residue at position 7 from the carboxyl terminus of CCK is critical for biological activity. The characteristic CCK-like activity depends on the sulfated Tyr residue at the seventh position. If the Tyr residue is not sulfated, or if another amino acid residue is present at this location, the peptide behaves as a gastrin analogue and loses its CCK-like potency.

The biological actions of $\mathrm{CCK}$ are mediated by 2 distinct receptors, the originally denoted CCK-A (alimentary type) and CCK-B (brain type), based on their anatomical location. They are now termed $\mathrm{CCK}_{1}$ and $\mathrm{CCK}_{2}$, respectively, because of the evidences indicating overlapping areas of location. ${ }^{10}$

Peptide YY (PYY), a 36 amino acid peptide, isolated from the porcine duodenum, has been known to be present in endocrine cells, pancreas and brain. ${ }^{11,12}$ PYY is found mainly in mucosal endocrine cells of the ileum, colon and rectum. ${ }^{12-14}$ In rats, it was shown to increase colonic motility, ${ }^{15}$ whereas it was reported to either increase or decrease small intestinal motility depending on species. ${ }^{13,16,17}$ It has been suggested that the release of PYY in postprandial state is mediated by CCK, and PYY was shown to be released from rat colon when $\mathrm{CCK}$ was administered intraarterially in an isolated, vascularly perfused rat colon. ${ }^{18}$

The major portion of neurons in human small and large intestines are cholinergic. A number of cells resembling enteroendocrine cells are found in the epithelium of the small and large bowels which contain choline acetyltransferase, a marker of cholinergic neurons. ${ }^{19}$

In the present study, using a totally isolated, vascularly perfused rat colon, we investigated: (1) the roles of CCK and PYY on colonic motility, (2) to determine if CCK modulates PYY release from the colon to influence the motility and (3) to clarify whether the action of CCK and PYY on colonic motility is mediated via the influence of cholinergic input.

\section{Materials and Methods}

\section{Materials}

Bovine serum albumin (BSA) and dextran were purchased from Sigma Chemical (St. Louis, MO, USA) and atropine sulfate from American Reagent (Shirley, NY, USA). Loxiglumide was a gift from the Rotta Research Laboratories (Milan, Italy). CCK-8 was purchased from Squibb Diagnostics (Princeton, NJ, USA) and PYY from Peninsula (Belmont, CA, USA). PYY antiserum was prepared in University of Rochester (Rochester, NY, USA) as described previously. ${ }^{20}$ Briefly, anti-PYY serum was produced in a New Zealand white rabbit by repeated immunization with PYY-BSA conjugate. The antiserum is highly specific for PYY. Except for a small crossreaction with neuropeptide Y $(1 \%)$ and avian pancreatic polypeptide $(0.01 \%)$, it did not crossreact with other unrelated gut peptides at concentration of 70 $\mathrm{ng} / \mathrm{mL}$ in the assay tube.

\section{Animal Preparation}

All experiments described in this report were approved by Animal Care Committee of the Chungbuk National University and University of Rochester. The operative procedure was similar to that previously described by Cuber et al for the isolated, vascularly perfused duodenojejunum ${ }^{21}$ and ileum of the rat. ${ }^{22}$ Male Sprague-Dawley rats weighing between 250 and $300 \mathrm{~g}$ were fasted for 48 hours with free access to tap water before surgery. Under anesthesia with intraperitoneal injection of xylazine $10 \mathrm{mg} / \mathrm{kg}$ and zolazepam $50 \mathrm{mg} / \mathrm{kg}$, the abdomen was opened by a midline incision. The stomach, spleen and small intestine were removed after ligation of the supplying blood vessels. The whole colon was freed of its visceral and retroperitoneal fixations. A polyethylene cannula $(0.58 \mathrm{~mm}$ ID, $0.96 \mathrm{OD})$ was then inserted in superior mesenteric artery and another one $(1.52 \mathrm{~mm}$ ID, $1.90 \mathrm{OD}$ ) into the portal vein, respectively. The arterial perfusion started immediately at a rate of $1.2 \mathrm{~mL} / \mathrm{min}$ with Krebs solution containing $0.1 \% \mathrm{BSA}$ and $3 \%$ dextran. The mixture was continuously gassed with $95 \% \mathrm{O}_{2}$ and $5 \% \mathrm{CO}_{2}$ and warmed at $37^{\circ} \mathrm{C}$. The preparation was removed approximately $8 \mathrm{~cm}$ in length and placed in a water bath at $37^{\circ} \mathrm{C}$. A rubber cannula $(5.0$ 
$\mathrm{mm} \mathrm{ID}, 6.5 \mathrm{~mm}$ OD) was inserted into both ends of the proximal and distal colon to drain the luminal secretion. The loop was then flushed out once or twice with $10 \mathrm{~mL}$ prewarmed $0.15 \mathrm{M} \mathrm{NaCl}$ gently. Microtip catheter pressure transducers $(2 \mathrm{~mm}$ diameter, Millar Inst Inc, Houston, TX, USA) were placed in $2.0 \mathrm{~cm}$ apart through the ends of the proximal and distal colon, separately (Fig. 1).

\section{Experimental Procedure}

Intraluminal pressure was monitored continuously via microtip catheter pressure transducers. The pressure changes were recorded with a Hewlett Packard 7754B system (Hewlett Packard Co, Palo Alto, CA, USA). From the recording, motility index was calculated by multiplying the amplitude by the duration of each contractile wave for 5-minute period and expressed as \% changes over basal period. All records were analyzed by one observer. Portal venous perfusate was collected as 15 minute fractions in ice-chilled glass tubes and frozen at $-20^{\circ} \mathrm{C}$ for subsequent determination of PYY level by the radioimmunoassay method described previously. ${ }^{20}$

\section{Effect of exogenous cholecystokinin-8 on colonic mo-} tility

After 30-minute basal period, CCK-8 at 12, 60 and $240 \mathrm{pM}$ were administered with each dose given for 15 minutes, starting with the lowest dose which was increased in stepwise fashion, while portal venous effluent was collected and frozen for future radioimmunoassay of PYY.

\section{Effect of exogenous peptide YY on colonic motility}

After 30-minute basal period, PYY at 12, 60 and $240 \mathrm{pM}$ were administered with each dose given for 15 minutes, starting with the lowest dose which was increased in stepwise fashion.

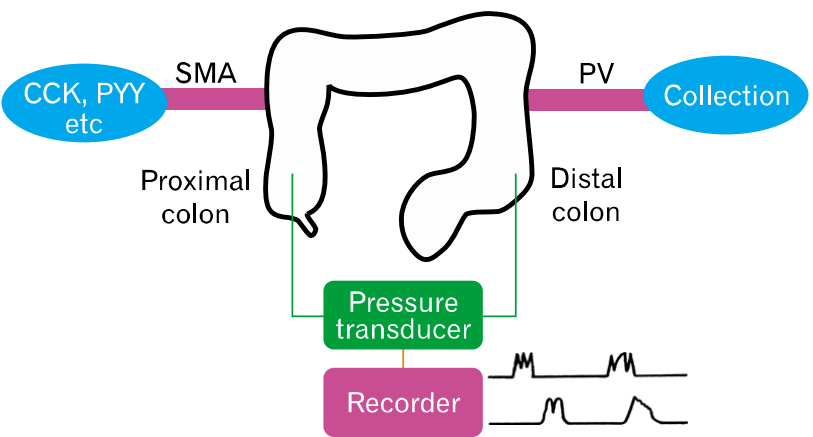

Figure 1. Schematic illustration of system used in an isolated vascularly perfused rat colon. CCK, cholecystokinin; PYY, peptide YY; SMA, superior mesenteric artery; PV, portal vein.
Effect of rabbit anti-peptide YY serum, loxiglumide and atropine on colonic motility stimulated by cholecystokinin-8

Effect of rabbit anti-peptide $Y Y$ serum on colonic motility stimulated by cholecystokinin-8. The effect of CCK-8 at $240 \mathrm{pM}$ was studied under the influence of a rabbit anti-PYY serum or a normal rabbit serum, given in $0.3 \mathrm{~mL}$ each. Portal venous perfusate was collected and frozen for radioimmunoassay of PYY.

Effect of loxiglumide on colonic motility stimulated by cholecystokinin-8. Under the influence of loxiglumide $\left(10^{-4} \mathrm{M}\right)$, the effect of CCK-8 at $240 \mathrm{pM}$ on colonic motility was studied. Portal venous perfusate was collected and frozen for radioimmunoassay of PYY.

Effect of atropine on colonic motility stimulated by cholecystokinin-8. Under the influence of atropine $\left(10^{-5} \mathrm{M}\right)$, the effect of CCK-8 at 240 pM on colonic motility was studied.

Effect of atropine on colonic motility stimulated by peptide $\boldsymbol{Y}$. Under the influence of atropine $\left(10^{-5} \mathrm{M}\right)$, the effect of PYY at $240 \mathrm{pM}$ on colonic motility was studied.

\section{Statistical Methods}

The data was expressed as mean \pm SE. Statistical analysis was performed using the SPSS for Windows version 10 (SPSS Inc, Chicago, IL, USA). Correlation analysis was used to determine the effect of CCK or PYY on colonic motility according to concentration. Wilcoxon rank-sum test was used to evaluate the inhibition of each drugs against stimulation of CCK or PYY on colonic motility. A $P$-value of $<0.05$ was considered statistically significant.

\section{Results}

\section{Effect of Exogenous Cholecystokinin-8 on Co- Ionic Motility}

CCK-8 dose-dependently stimulated the colonic motility. Both in the proximal and distal colon, the percentage changes over basal motility indices in response to 3 different doses of CCK-8 (12, 60 and $240 \mathrm{pM})$ were significantly increased to $59 \%$ $\pm 20 \%$ and $24 \% \pm 6 \%, 67 \% \pm 26 \%$ and $79 \% \pm 28 \%$ and $112 \% \pm 22 \%$ and $134 \% \pm 52 \%$, respectively, which were statistically significant (Fig. 2, 9A and 10A). Interestingly, after CCK-8 at doses of 12, 60 and 240 pM, integrated PYY release (fmol/15 min) from portal effluent was significantly increased 


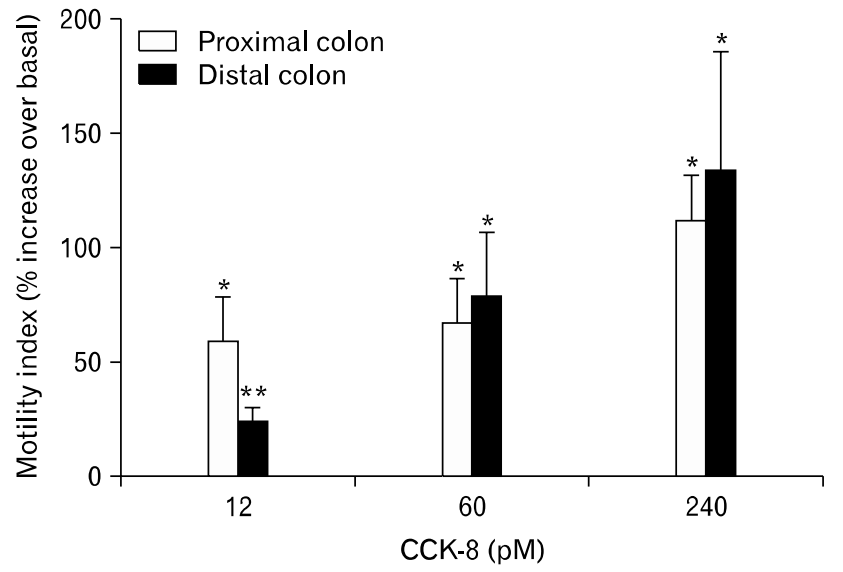

Figure 2. Effect of intraarterial infusion of cholecystokinin-8 (CCK-8) on the colonic motility. Data were presented as \% increases over the basal period in response to CCK-8 at doses of 12, 60 and $240 \mathrm{pM}$. Each bar represents mean $\pm \mathrm{SE}$ of 7 experiments. ${ }^{*} P<0.05,{ }^{*} P<0.01$ vs basal values.

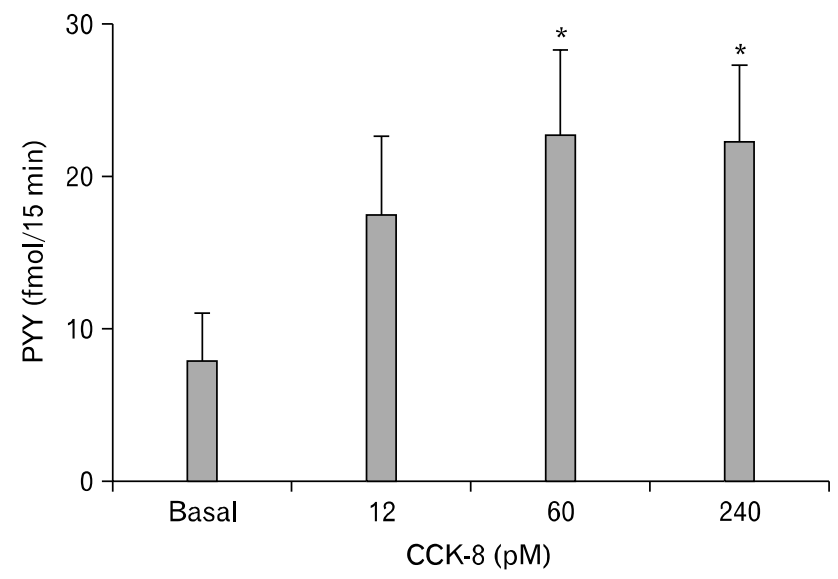

Figure 3. Integrated release of peptide YY found in the potal effluent in response to intraarterial infusion of cholecystokinin-8 at doses of 0,12 , 60 and 240 pM. CCK-8, cholecystokinin-8; PYY, peptide YY. Each bar represents mean $\pm \mathrm{SE}$ of 6 experiments. ${ }^{*} P<0.05$ vs basal values.

from $8.0 \pm 3.1$ to $17.5 \pm 5.3,22.8 \pm 5.6$ and $22.3 \pm 5.1$, respectively (Fig. 3). The increase in colonic motility paralleled the increase in PYY release from the portal effluent.

\section{Effect of Exogenous Peptide YY on Colonic Motility}

In the proximal colon, the increases in the motility over basal values in response to 3 different doses of PYY (12, 60 and 240 $\mathrm{pM}$ ) were $22 \% \pm 7 \%, 27 \% \pm 7 \%$ and $33 \% \pm 11 \%$, respectively, which were statistically significant. In the distal colon, the mo-

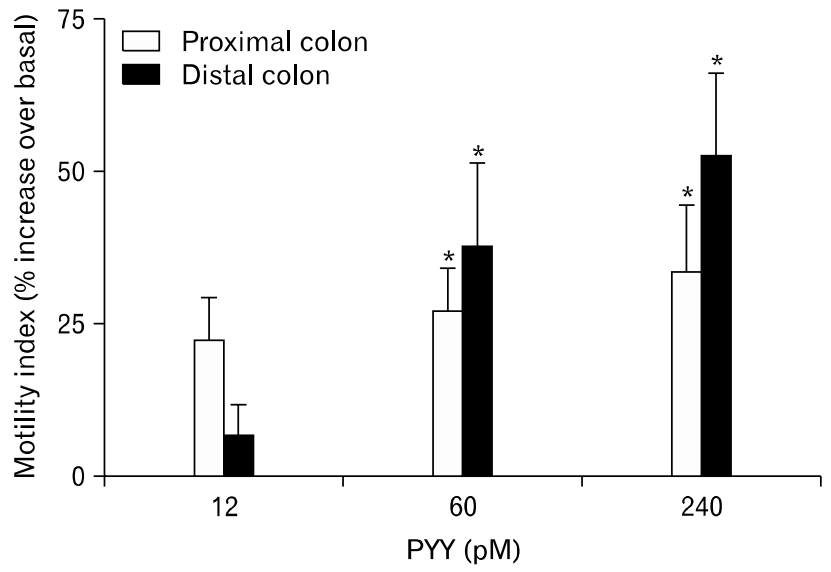

Figure 4. Effect of intraarterial infusion of peptide YY (PYY) on the colonic motility. Data were expressed as \% increase over basal period in response to PYY at doses of 12,60 and $240 \mathrm{pM}$. Each bar represents mean $\pm \mathrm{SE}$ of 6 experiments. ${ }^{*} P<0.05$ vs basal values.

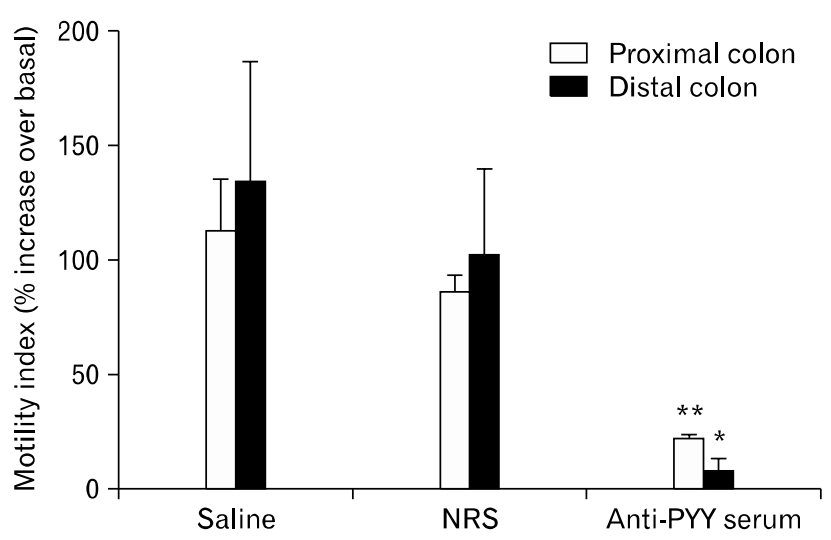

Figure 5. Effect of cholecystokinin-8 (CCK-8) at $240 \mathrm{pM}$, on the colonic motility under the influence of saline, normal rabbit serum (NRS) or rabbit anti-peptide YY serum. PYY, pepdite YY. Each bar represents mean $\pm \mathrm{SE}$ of $5-7$ experiments. ${ }^{*} P<0.05,{ }^{*} P<0.01$ vs CCK- $8+$ NRS.

tility index over basal values dose-dependently increased to $6 \% \pm$ $5 \%, 37 \% \pm 13 \%$ and $52 \% \pm 13 \%$, respectively, which were also statistically significant (Fig. 4, 9B and 10B). Thus, PYY significantly and dose-dependently increased colonic motility both in the proximal and distal colon, although the magnitude of increase achieved by PYY was significantly less potent than that by CCK-8 at the doses employed. 


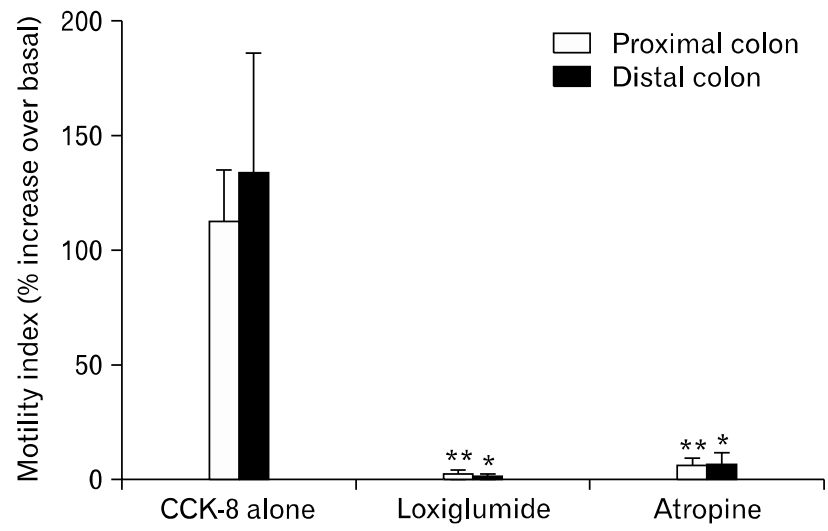

Figure 6. Effect of loxiglumide $\left(10^{-4} \mathrm{M}\right)$ and atropine $\left(10^{-5} \mathrm{M}\right)$ on cholecystokinin-8 (CCK-8, $240 \mathrm{pM})$ stimulated colonic motility. Each bar represents mean $\pm \mathrm{SE}$ of 7 experiments. ${ }^{*} P<0.05,{ }^{*} * P<0.01$ vs CCK-8 alone.

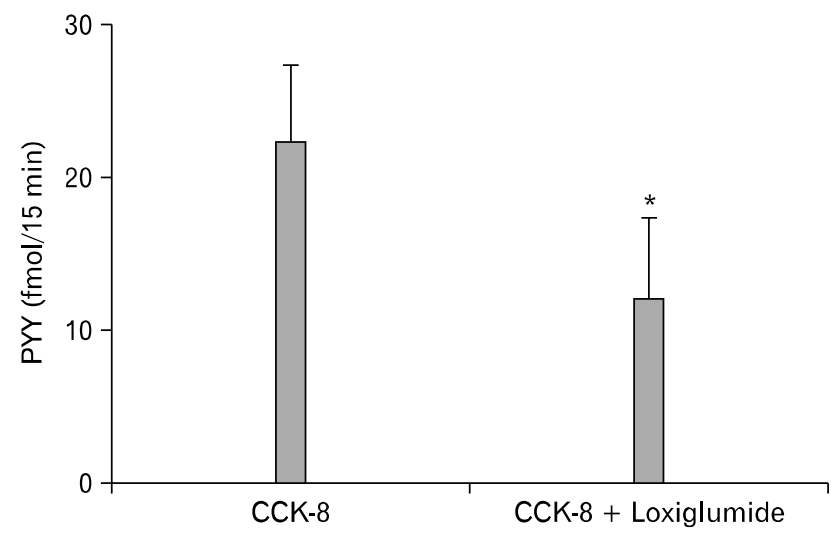

Figure 7. Effect of loxiglumide $\left(10^{-4} \mathrm{M}\right)$ on peptide $\mathrm{YY}$ release in portal effluent in response to cholecystokinin-8 (CCK-8, $240 \mathrm{pM})$ infusion. PYY, peptide YY. Each bar represents mean \pm SE of 7 experiments. ${ }^{*} P<0.05$ vs CCK- 8 alone.

Effect of Rabbit Anti-Peptide YY Serum, Loxiglumide and Atropine on Colonic Motility Stimulated by Cholecystokinin- 8

Effect of rabbit anti-peptide YY serum on colonic motility stimulated by cholecystokinin-8

The infusion of a rabbit anti-PYY serum resulted in a profound decrease in the motility index both in the proximal and distal colon $(21.9 \% \pm 1.5 \%$ and $8.1 \% \pm 5.0 \%, P<0.05)$, whereas it was not influenced by a normal rabbit serum (Fig. 5, 9C, 9D, $10 \mathrm{C}$ and 10D). PYY antibody completely abolished the release of portal PYY stimulated by CCK-8 (data not shown).

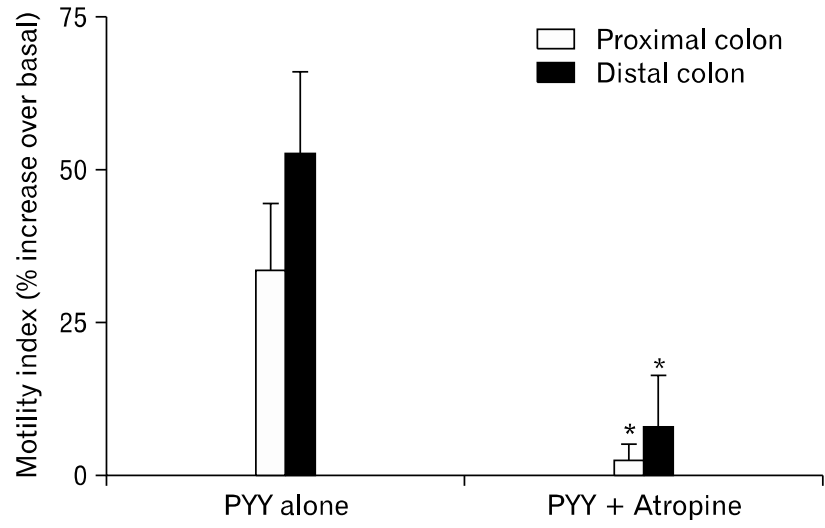

Figure 8. Effect of atropine $\left(10^{-5} \mathrm{M}\right)$ on peptide YY (PYY, $\left.240 \mathrm{pM}\right)$ stimulated colonic motility. Each bar represents mean \pm SE of 6 experiments. ${ }^{*} P<0.05$ vs PYY alone.

\section{Effect of loxiglumide on colonic motility stimulated by cholecystokinin-8}

Under $10^{-4} \mathrm{M}$ of loxiglumide background, the CCK action to stimulate colonic motility was almost completely abolished and the representing motility indices were $2.4 \% \pm 2.1 \%$ and $1.5 \% \pm 1.0 \%$, above basal respectively from the proximal colon and distal colon $(P<0.05)$ (Fig. 6, 9E and 10E). PYY release in portal perfusate was also decreased by loxiglumide from 22.3 $\pm 5.1 \mathrm{fmol} / 15 \mathrm{~min}$ during $\mathrm{CCK}$ alone to $12.0 \pm 5.4 \mathrm{fmol} / 15$ min after pretreatment with loxiglumide (Fig. 7).

Effect of atropine on colonic motility stimulated by cholecystokinin-8

After atropine $\left(10^{-5} \mathrm{M}\right)$, the $\mathrm{CCK}$ action to stimulate colonic motility was almost completely abolished revealing motility indices from the proximal and distal colon; $5.9 \% \pm 3.8 \%$ and $6.5 \%$ $\pm 5.4 \%$ above basal (proximal colon, $P<0.05$; distal colon, $P$ $<0.05$ vs $240 \mathrm{pM}$ of CCK) (Fig. 6, 9F and 10F).

Effect of atropine on colonic motility stimulated by peptide YY

The stimulation by PYY of colonic motility was almost completely blocked by atropine in the proximal colon and distal colon $(2.6 \% \pm 2.6 \%$ and $8.2 \% \pm 8.2 \% ; P<0.05)$ (Fig. $8,9 \mathrm{G}$ and $10 \mathrm{G})$.

\section{Discussion}

The gut endocrine cells are highly sensitive to ischemia and, therefore, their preserved ability to secrete hormones suggests perfused organ mobility. The isolated perfused rat colon is a use- 
A $\mathrm{cmH}_{2} \mathrm{O}$
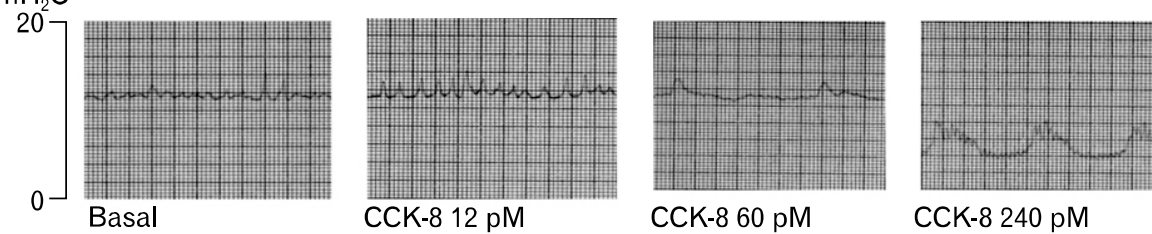

CCK-8 60 pM

CCK-8 240 pM
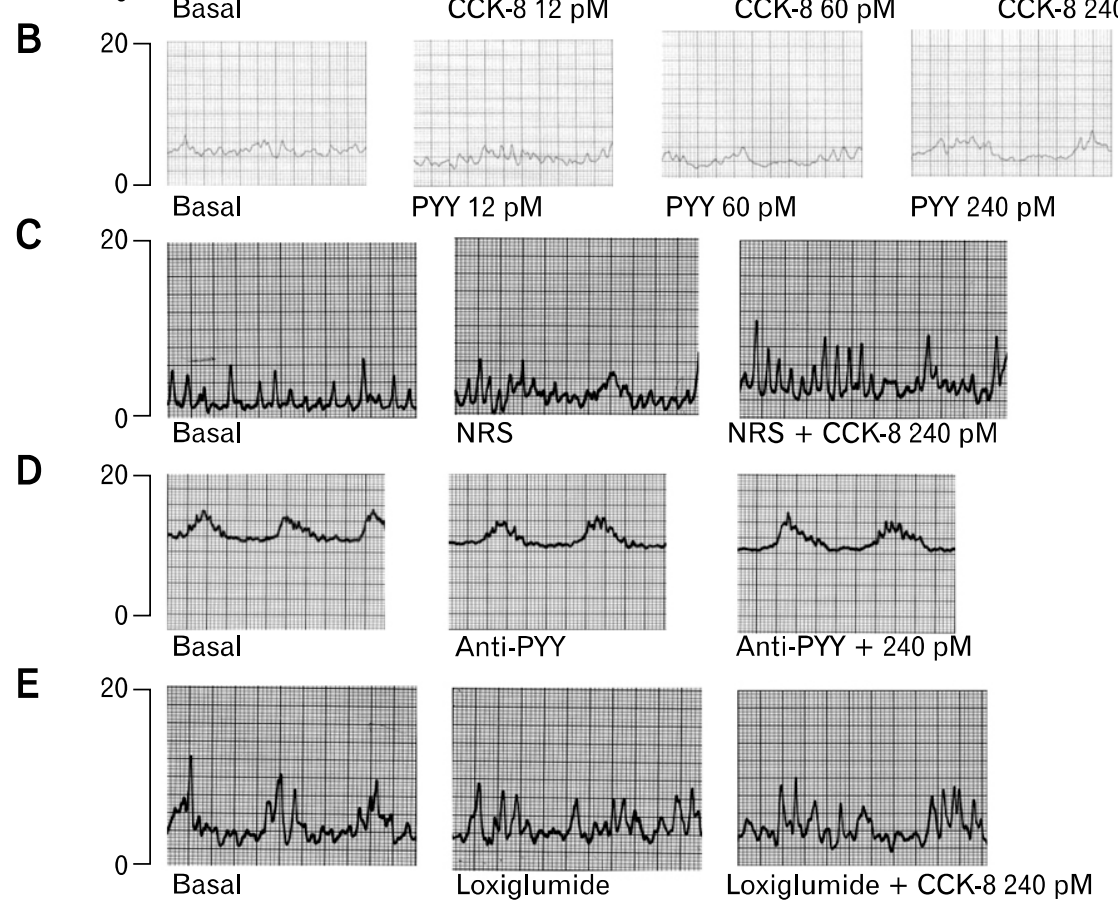

Anti-PYY

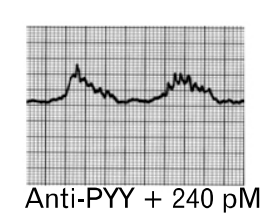

F
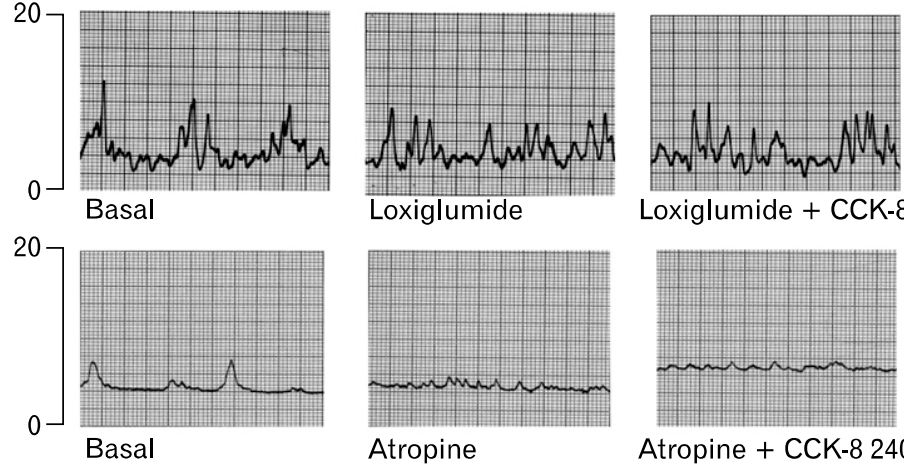

Loxiglumide + CCK-8 240 pM

Atropine

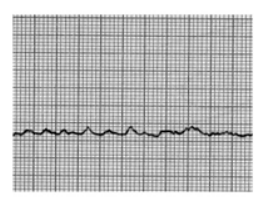

Atropine + CCK-8 $240 \mathrm{pM}$

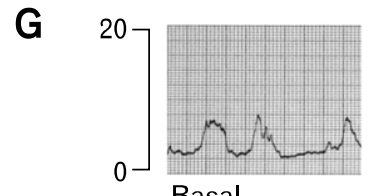

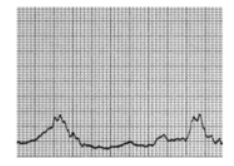

Atropine

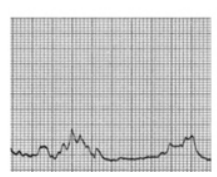

Atropine + PYY $240 \mathrm{pM}$
Figure 9. Representative traces response of isolated rat colon to intraarterial infusion of agents in proximal colon. Response of rat colon to intraarterial infusion of cholecystokinin-8 (CCK-8) (A) and peptide YY (PYY) (B) in proximal colon. The effect of normal rabbit serum (C), anti-PYY serum (D), loxiglumide (E) and atropine (F) on proximal colonic motility stimulated by CCK-8. The effect of atropine $(\mathrm{G})$ on proximal colonic motility stimulated by PYY. NRS, normal rabbit serum. ful tool for the investigation of colonic endocrine function and secretion. $^{23}$

CCK was first discovered in 1928 based on the ability of intestinal extracts to stimulate gallbladder contraction in dogs, and was later identified in 1966 from porcine intestine due to its recognition as a potent stimulant in pancreatic enzyme secretion. ${ }^{1}$

CCK-8 has been reported to stimulate in vitro colonic muscle strips, ${ }^{4,24}$ and intact colon of canine ${ }^{25}$ and human, ${ }^{6,7}$ whereas it was also reported to inhibit colonic motility in humans. ${ }^{8,9}$ In our study, the motor activity of isolated vascularly perfused rat colon, including both right and left colon, as measured by intraluminal pressure changes, was stimulated by exogenous CCK-8.

Loxiglumide is a potent and specific $\mathrm{CCK}_{1}$ receptor antagonist which blocks the $\mathrm{CCK}$ action on colon, gallbladder, pancreas and stomach in both experimental animals and humans. ${ }^{3,26} \mathrm{Al}-$ though $\mathrm{CCK}_{1}$ and $\mathrm{CCK}_{2}$ receptors are present both in central nervous system and various peripheral organs, the $\mathrm{CCK}_{2}$ receptor is predominantly present in central nervous system. In the intestine, as is in most regions of the gastrointestinal tract, CCK receptors on smooth muscle cells are $\mathrm{CCK}_{1}$ type. It has long been known the gastrin and $\mathrm{CCK}_{2}$ receptors to be similar. The $\mathrm{CCK}_{1}$ receptor has an approximately 1,000-fold greater affinity for CCK 
A $\mathrm{cmH}_{2} \mathrm{O}$
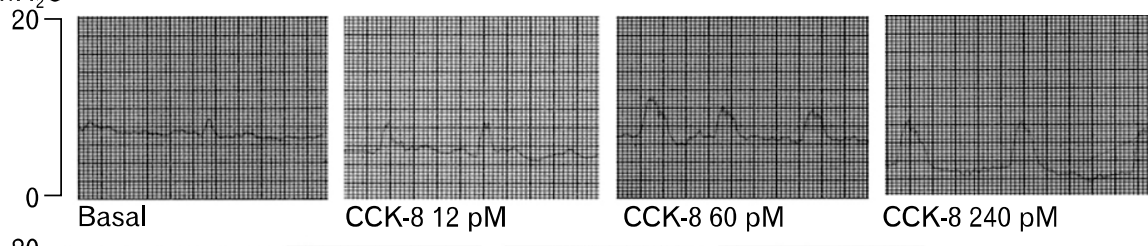

B

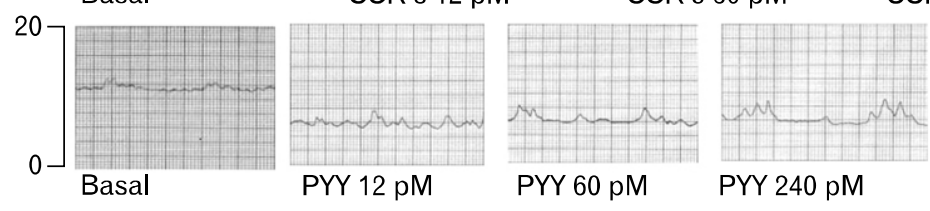

C
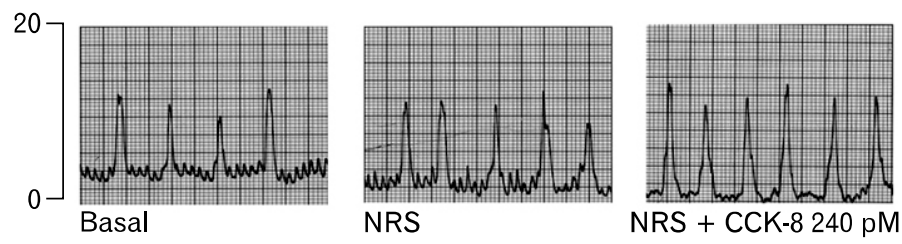

D

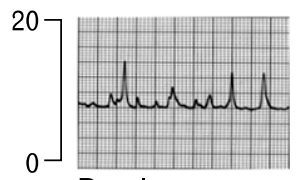

E
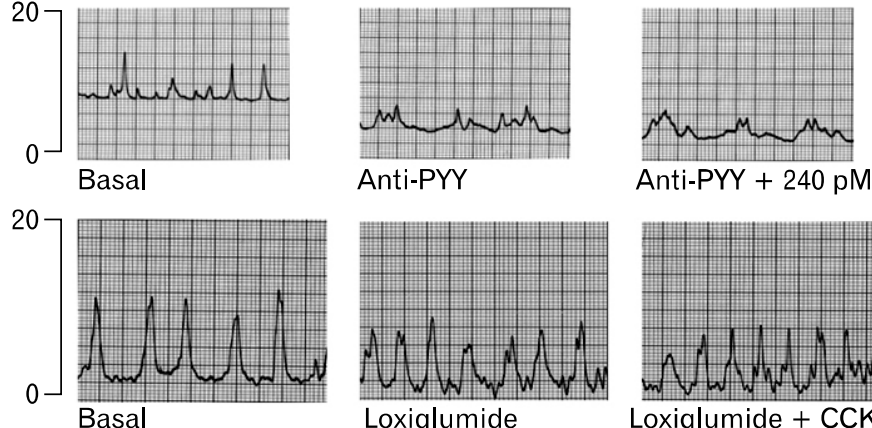

Anti-PYY

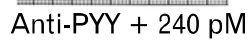

$\mathbf{F}$
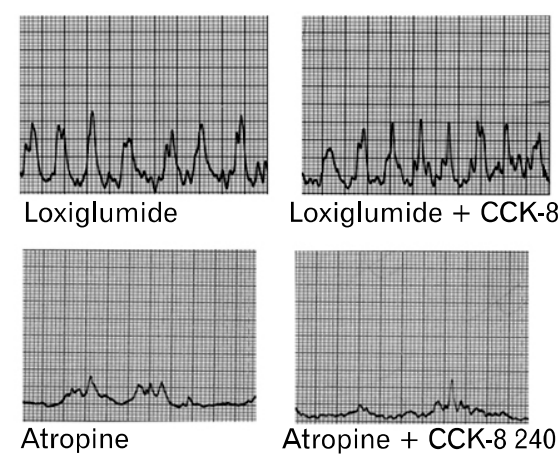

Loxiglumide + CCK-8 240 pM

Figure 10. Representative traces response of isolated rat colon to intraarterial infusion of agents in distal colon. Response of rat colon to intraarterial infusion of cholecystokinin-8 (CCK-8) (A) and peptide YY (PYY) (B) in distal colon. The effect of normal rabbit serum (C), antiPYY serum (D), loxiglumide (E) and atropine $(\mathrm{F})$ on distal colonic motility stimulated by CCK- 8 . The effect of atropine (G) on distal colonic motility stimulated by PYY. NRS, normal rabbit serum.

than for gastrin, while the $\mathrm{CCK}_{2}$ receptor has the same high affinity for both $\mathrm{CCK}$ and gastrin. $\mathrm{CCK}_{1}$ receptor responds to sulfated CCK with a 1,000-fold greater potency than non-sulfated CCK. These receptors are characteristically activated by sulfated CCK much more potently than by desulfated CCK or sulfated and desulfated gastrin, and are blocked by the benzodiazepine derivative, L364,718. ${ }^{26,27}$ It has long been known that $\mathrm{CCK}_{1}$ receptor antagonist is able to shorten colonic transit time. ${ }^{28}$ On the other hand loxiglumide has been shown to interfere with the gastrocolonic reflex and ileal motility and is able to selectively slow colonic transit time in patients suffering from IBS. ${ }^{29}$ In the pres- ent study, the stimulating effect of CCK-8 was completely abolished by loxiglumide.

One of the study provided data regarding the distribution of $\mathrm{CCK}_{1}$ receptors in human colon by using receptor autoradiography, and it was shown that the main target of CCK was the myenteric plexus, which predominantly occupied by $\mathrm{CCK}_{1}$ receptors. In addition, $\mathrm{CCK}_{1}$ receptors were distributed at a moderate-tolow density in the longitudinal muscle, while the circular muscle had no $\mathrm{CCK}_{1}$ receptors. ${ }^{30}$ These data suggest that CCK affects colonic motility by fundamentally 2 different pathways: acting on neurons in the myenteric plexus and directly on the smooth mus- 
cle cells.

In the ileum of guinea pig, CCK was shown to stimulate local neuronal release of acetylcholine at the neuromuscular junction. ${ }^{31}$ Intraarterial CCK-8 was also shown to produce circular muscle contraction of the canine proximal colon that is mediated by stimulation of specific CCK receptors which stimulate the release of acetylcholine from cholinergic neurons. ${ }^{25}$ In one study, motility patterns were compared between healthy volunteers and IBS patients with abdominal pain and frequent defecation or diarrhea. The motility index, the frequency of high-amplitude propagating complexes, and also the responses to $\mathrm{CCK}$ were significantly greater in this subset of IBS patients. ${ }^{32}$ The effect of CCK were profoundly inhibited by both loxiglumide and atropine.

The effect of PYY on the colonic motility depends on species. In the guinea pig and cat, PYY was shown to inhibit both small intestinal and colonic motility. In the canine, PYY stimulate small intestinal motility. In the rat, PYY inhibit small intestinal motility and stimulate colonic motility. ${ }^{13,15-17}$ In our study, PYY increased colonic motility in the proximal and distal colon.

PYY is not confined to distal intestinal endocrine cells in the dog but is also an enteric neuropeptide with maximal concentrations being present in the intestinal myenteric plexus. ${ }^{16}$ It was shown to stimulate circular muscle contractions of the isolated perfused canine ileum by enhancing acetylcholine release. ${ }^{33}$ Electrical stimulation of the vagus nerve in dogs resulted in release of PYY. This data suggests that food-stimulated PYY secretion is dependent on ganglionic transmission and an atropine-blockable postganglionic parasympathetic pathway. ${ }^{34}$ The action of PYY appears to heavily depend on the local release of acetylcholine. This implies that its action is mediated via the release of acetylcholine by PYY or it may require local cholinergic tone.

Postprandial PYY release is CCK dependent in dogs. ${ }^{35}$ Plasma PYY increased with fat, but plasma PYY level was lower following CCK receptor antagonist. CCK serves as a foregut signal linking fat in the proximal gut with the release of distal gut PYY. ${ }^{36}$ Release of PYY by fat in the proximal but not distal gut depends on an atropine-sensitive cholinergic pathway. ${ }^{37}$ When proximal gut contact with fats, the PYY is released via an indirect mechanism (CCK and cholinergic pathways); whereas in distal gut, the PYY is released via a direct mechanism (exposure of PYY releasing cells to fat). ${ }^{36}$ In our study, the effect of CCK-8 on increasing colonic motility is parallel with the increase in PYY release from colon. Moreover, the PYY has shown to increase colonic motility in proximal and distal colon as well, although it is not as potent as CCK-8 at the doses employed. It was of consid- erable interest to note that the CCK-stimulated colonic motility was profoundly inhibited by both the anti-PYY serum, and loxiglumide, accompanied by complete or significant inhibition of the release of PYY stimulated by CCK. These results suggest that CCK-8 induced colonic motility is significantly mediated by PYY.

The pancreatic polypeptide (PP) family consists of 3 peptides; PP, PYY and neuropeptide Y. All 3 peptides are found both in the central nervous system and in peripheral tissue, and they show a characteristic distribution in the digestive tract. ${ }^{13,38}$ The antiserum used in the present study was highly specific for PYY except for a small crossreaction with neuropeptide Y (1\%), and avian PP $(0.01 \%)$. As described previously, radioimmunoassay for PYY that we used was specific for PYY. ${ }^{20}$ It should be noted that the amount of PYY released after CCK-8 is relatively small, but effect of immunoneutralization of PYY on CCK-stimulated colonic motility was profound. This may be attributed to a possibility of PYY to exert as a paracrine or neurocrine messenger. It has been reported that enteric nervous system contains large amount of PYY in the dog. ${ }^{16}$ Since both neuropeptide Y and PP stimulate the colonic motility, it is possible that the effect of either 1 of these 2 in small quantity could have been blocked by the anti-PYY serum because of its cross reaction within the 2 peptides.

We conclude that CCK-8 may increase colonic motility via $\mathrm{CCK}_{1}$ receptor and its action is partly mediated by PYY with the requirement for cholinergic input in increasing the motility by either PYY or CCK.

\section{References}

1. Jorpes E, Mutt V. Cholecystokinin and pancreozyme, one single hormone? Acta Physiol Scand 1966;66:196-202.

2. Liddle RA. Cholecystokinin cells. Annu Rev Physiol 1997;59:221242.

3. Niederau C, Heintges T, Rovati L, Strohmeyer G. Effects of loxiglumide on gallbladder emptying in healthy volunteers. Gastroenterology 1989;97:1331-1336.

4. Niederau C, Karaus M. Effects of agonists and antagonists of cholecystokinin on contractile and myoelectric activity of isolated muscle of colon and ileum in the dog and guinea pig. Neurogastroenterol Motil 1990;2:169-175.

5. Harvey RF, Read AE. Effect of cholecystokinin on colonic motility and symptoms in patient with the irritable bowel syndrome. Lancet 1973;1:1-3

6. Snape WJ Jr, Metarazzo SA, Cohen S. Effect of eating and gastrointestinal hormones on human colonic myoelectrical and motor activity. Gastroenterology 1978;75:373-378. 
7. Dinoso VP Jr, Meshkinpour H, Lorber SH, Gutierrez JG, Chey WY. Motor responses of the sigmoid colon and rectum to exogenous cholecystokinin and secretin. Gastroenterology 1973;65:438-444.

8. Mangel AW, Brazer SR, Smith JW, Fitz JG, Taylor IL. Inhibition of colonic motility by cholecystokinin. Ann Med 1992;24:341-342.

9. Kellow JE, Miller LJ, Phillips SF, Haddad AC, Zinsmeister AR, Charboneau JW. Sensitivities of human jejunum, ileum, proximal colon, and gallbladder to cholecystokinin octapeptide. Am J Physiol 1987;252(3 Pt 1):G345-G356.

10. Noble F, Wank SA, Crawley JN, et al. International Union of Pharmacology. XXI. Structure, distribution, and functions of cholecystokinin receptors. Pharmacol Rev 1999;51:745-781.

11. Tatemoto K. Isolation and characterization of peptide YY (PYY), a candidate gut hormone that inhibits pancreatic exocrine secretion. Proc Natl Acad Sci USA 1982;79:2514-2518.

12. Adrian TE, Ferri GL, Bacarese-Hamilton AJ, Fuessl HS, Polak JM, Bloom SR. Human distribution and release of a putative new gut hormone, peptide YY. Gastroenterology 1985;89:1070-1077.

13. Lundberg JM, Tatemoto K, Terenius L, et al. Localization of peptide YY (PYY) in gastrointestinal endocrine cells and effects on intestinal blood flow and motility. Proc Natl Acad Sci USA 1982;79: 4471-4475.

14. Greeley GH Jr, Hill FL, Spannagel A, Thompson JC. Distribution of peptide YY in the gastrointestinal tract of the rat, dog, and monkey. Regul Pept 1987;19:365-372.

15. Wager-Pagé SA, Ghazali B, Anderson W, Veale WL, Davison JS. Neuropeptide Y, peptide YY, and pancreatic polypeptide modulate duodenal and colonic motility at a thoracic spinal site in rats. Peptides 1992;13:807-813.

16. McDonald TJ, Wang YF, Mao YK, Broad RM, Cook MA, Daniel EE. PYY: a neuropeptide in the canine enteric nervous system. Regul Pept 1993;44:33-48.

17. Al-Saffar A, Hellström PM, Nylander G. Correlation between peptide YY-induced myoelectric activity and transit of small intestinal contents in rats. Scand J Gastroenterol 1985;20:577-582.

18. Plaisancié P, Bernard C, Chayvialle JA, Cuber JC. Release of peptide YY by neurotransmitters and gut hormones in the isolated, vascularly perfused rat colon. Scand J Gastroenterol 1995;30:568-574.

19. Porter AJ, Wattchow DA, Brookes SJ, Schemann M, Costa M. Choline acetyltransferase immunoreactivity in the human small and large intestine. Gastroenterology 1996;111:401-408.

20. Jin H, Cai L, Lee K, et al. A physiological role of peptide YY on exocrine pancreatic secretion in rats. Gastroenterology 1993;105: 208-215

21. Cuber JC, Vilas F, Charles N, Bernard C, Chayvialle JA. Bombesin and nutrients stimulate release of CCK through distinct pathways in the rat. Am J Physiol 1989;256(6 Pt 1):G989-G996.

22. Cuber JC, Herrmann C, Kitabgi P, et al. Neuromedin-N is not released with neurotensin from rat ileum. Endocrinology 1990;126:
1584-1592.

23. Herrmann-Rinke C, Eissele R, Arnold R, Göke B. Studies on the viability of the isolated vascularly perfused rat colon. Digestion 1996; 57:349-355.

24. Egberts EH, Johnson AG. The effect of cholecystokinin on human taenia coli. Digestion 1977;15:217-222.

25. Barone FC, Bondinell WE, Labosh TJ, White RF, Ormsbee HS 3rd. Cholecystokinin stimulates neuronal receptors to produce contraction of the canine colon. Life Sci 1989;44:533-542.

26. Grider J, Makhlouf GM. Distinct receptors for cholecystokinin and gastrin on muscle cells of stomach and gallbladder. Am J Physiol 1990;259(2 Pt 1):G184-G190.

27. Morini G, Barocelli E, Impicciatore M, Grider JR, Makhlouf GM. Receptor type for cholecystokinin on isolated muscle cells of the guinea pig. Regul Pept 1990;28:313-321.

28. Meyer BM, Werth BA, Beglinger C, et al. Role of cholecystokinin in regulation of gastrointestinal motor functions. Lancet 1989;2:12-15.

29. Varga G, Bálint A, Burghardt B, D'Amato M. Involvement of endogenous $\mathrm{CCK}$ and $\mathrm{CCK}_{1}$ receptors in colonic motor function. $\mathrm{Br} \mathrm{J}$ Pharmacol 2004;141:1275-1284.

30. Rettenbacher M, Reubi JC. Localization and characterization of neuropeptide receptors in human colon. Naunyn Schmiedebergs Arch Pharmacol 2001;364:291-304.

31. Vizi SE, Bertaccini G, Impicciatore M, Knoll J. Evidence that acetylcholine released by gastrin and related polypeptides contributes to their effect on gastrointestinal motility. Gastroenterology 1973;64: 268-277.

32. Chey WY, Jin HO, Lee MH, Sun SW, Lee KY. Colonic motility abnormality in patients with irritable bowel syndrome exhibiting abdominal pain and diarrhea. Am J Gastroenterol 2001;96:1499-1506.

33. Fox-Threlkeld JA, Daniel EE, Christinck F, Woskowska Z, Cipris S, McDonald TJ. Peptide YY stimulates circular muscle contractions of the isolated perfused canine ileum by inhibiting nitric oxide release and enhancing acetylcholine release. Peptides 1993;14:11711178 .

34. Zhang T, Uchida T, Gomez G, Lluis F, Thompson JC, Greeley GH Jr. Neural regulation of peptide YY secretion. Regul Pept 1993;48: 321-328.

35. McFadden DW, Rudnicki M, Kuvshinoff B, Fischer JE. Postprandial peptide YY release is mediated by cholecystokinin. Surg Gynecol Obstet 1992;175:145-150.

36. Lin HC, Chey WY, Zhao X. Release of distal gut peptide YY (PYY) by fat in proximal gut depends on CCK. Peptides 2000;21:15611563.

37. Lin HC, Taylor IL. Release of peptide YY by fat in the proximal but not distal gut depends on an atropine-sensitive cholinergic pathway. Regul Pept 2004;117:73-76.

38. Onaga T, Zabielski R, Kato S. Multiple regulation of peptide YY secretion in the digestive tract. Peptides 2002;23:279-290. 